\title{
Examination of zinc in the circadian system
}

\author{
Mahtab Moshirpour ${ }^{1,2}$, Amy S. Nakashima ${ }^{1,2}$, Nicole Sehn ${ }^{1}$, Victoria M. Smith ${ }^{1,2}$, \\ Richard H. Dyck ${ }^{1,2,3}$ \& Michael C. Antle ${ }^{1,2,4 \dagger}$
}

${ }^{1}$ Department of Psychology, ${ }^{2}$ Hotchkiss Brain Institute, ${ }^{3}$ Department of Cell Biology and Anatomy, ${ }^{4}$ Department of Physiology \& Pharmacology, University of Calgary, Calgary, Alberta, Canada

Words: 8456

Pages: 44

Figures: 9

$†$ †orresponding Author: Department of Psychology

University of Calgary

Calgary, AB, Canada

T2N $1 \mathrm{~N} 4$

Phone: $+1(403)$ 220-2574

Fax: $\quad+1(403) 282-8249$

Email: antlem@ucalgary.ca

\section{Acknowledgements}

This work was supported by Natural Sciences and Engineering Research Council of Canada (NSERC) Discovery Grants to RHD and MCA and by a Canadian Institutes of Health Research (CIHR) Operating Grant to RHD. 


\begin{abstract}
Zinc is a trace element that is essential for a large number of biological and biochemical processes in the body. In the nervous system zinc is packaged into synaptic vesicles by the ZnT3 transporter, and synaptic release of zinc can influence the activity of postsynaptic cells, either directly though its own cognate receptors, or indirectly by modulating activation of receptors for other neurotransmitters. Here, we explore the anatomical and functional aspects of zinc in the circadian system. Melanopsin-containing retinal ganglion cells in the mouse retina were found to colocalize ZnT3, indicating that they can release zinc at their synaptic targets. While the master circadian clock in the hamster suprachiasmatic nucleus ( $\mathrm{SCN})$ was found to contain, at best, sparse zincergic input, the intergeniculate leaflet (IGL) was found to have prominent zincergic input. Levels of zinc in these areas were not affected by time of day. Additionally, IGL zinc staining persisted following enucleation, indicating other prominent sources of zinc instead of, or in addition to, the retina. Neither enhancement nor chelation of free zinc at either the SCN or IGL altered circadian responses to phase-shifting light in hamsters. Finally, entrainment, freerunning, and circadian responses to light were explored in mice lacking the ZnT3 gene. In every aspect explored, the ZnT3-KO mice were not significantly different from their wildtype counterparts. These findings highlight the presence of zinc in areas critical for circadian functioning but have yet to identify a role for zinc in these areas.
\end{abstract}

Keywords: $\mathrm{Zn}^{2+}$, rhythms, photic, c-fos, mper1, ipRGCs 


\section{Highlights}

- The synaptic zinc transporter ZnT3 is found in melanopsin-containing retinal ganglion cells.

- While zinc input to the hamster SCN was found to be sparse at best, prominent zincergic staining was found throughout the IGL.

- Zinc levels in the SCN and IGL did not change between the night and day.

- Neither increasing nor decreasing zinc levels in either the SCN or IGL had an influence on circadian responses to light.

- Mice lacking the ZnT3 transporter did not differ from wildtype mice on a wide variety of circadian measures. 


\section{Abbreviations}

ANOVA Analysis of variance

AVP Arginine vasopressin

CT Circadian time

DD Constant darkness

dLGN Dorsolateral geniculate nucleus

DMSO Dimethyl sulfoxide

GABA $\gamma$-aminobutyric acid

GCL Ganglion cell layer

GHT Geniculohypothalamic tract

GRP Gastrin-releasing peptide

$\mathrm{I}_{\mathrm{A}} \quad$ Transient potassium current

IGL Intergeniculate leaflet

INL Inner nuclear layer

i.p. Intraperitoneal

IR Immunoreactive

IPL Inner plexiform layer

ipRGCs Intrinsically photosensitive retinal ganglion cells

KO Knockout

LD Light-dark cycle

LP Light pulse

NMDAR N-methyl-D-aspartate receptor

NPY Neuropeptide Y 


\begin{tabular}{|c|c|}
\hline OPL & Outer plexiform layer \\
\hline PBS & Phosphate buffered saline \\
\hline PBSx & PBS with Triton-X-100 \\
\hline PCR & Polymerase chain reaction \\
\hline PFA & Paraformaldehyde \\
\hline psi & Phase angle of entrainment \\
\hline $\mathrm{SCN}$ & Suprachiasmatic nucleus \\
\hline SD & Standard deviation \\
\hline SEM & Standard error of the mean \\
\hline TPEN & $\mathrm{N}, \mathrm{N}, \mathrm{N}^{\prime}, \mathrm{N}-\mathrm{Tetrakis}$ (2-pyridylmethyl) ethylenediamine \\
\hline VGLUT1 & Vesicular glutamate transporter 1 \\
\hline VIP & Vasoactive intestinal polypeptide \\
\hline vLGN & Ventrolateral geniculate nucleus \\
\hline WT & Wildtype \\
\hline ZIP & ZRT/IRT-like proteins \\
\hline $\mathrm{ZnCl}_{2}$ & Zinc Chloride \\
\hline $\mathrm{ZnT}$ & Zinc transporter \\
\hline ZnT3 & Zinc transporter 3 \\
\hline ZT & Zeitgeber time \\
\hline
\end{tabular}




\section{INTRODUCTION}

Daily rhythms in physiology and behavior are regulated in mammals by the master circadian clock located in the suprachiasmatic nucleus (SCN;Antle and Silver, 2005). This clock receives input from the retina so that the rhythms it generates are coordinated with the light/dark cycle of the environment (Rusak and Zucker, 1979). Specialized intrinsically photosensitive retinal ganglion cells (ipRGCs) that use the photopigment melanopsin provide information about environmental light to the circadian system (Berson et al., 2002; Hattar et al., 2002; Moore et al., 1995; Provencio et al., 2000). Axons from these ipRGCs give rise to the retinohypothalamic tract that innervates the ventrolateral region of the $\mathrm{SCN}$, and uses glutamate as its primary neurotransmitter (Ebling, 1996). The circadian clock also receives input from other brain regions, and these inputs can modulate how the circadian clock responds to light and glutamate. Serotonin from the raphe nuclei attenuates responses to light and glutamate (Antle et al., 2003;Mistlberger and Antle, 1998;Rea et al., 1994). The retinorecipient intergeniculate leaflet (IGL) provides NPY-ergic innervation to the SCN that also opposes circadian responses to light (Biello et al., 1997). Identifying other such modulatory substances could help in treating sleep and circadian disorders. One such candidate is the divalent cation zinc.

The signaling pool of zinc is found in the brain, stored in vesicles of glutamatergic neurons in the cortex, amygdala and hippocampus (Brown and Dyck, 2004) from which it is released and can act as a co-transmitter and neuromodulator at post-synaptic terminals. Zinc is packaged into vesicles exclusively through the ZnT3 transporter (slc30a3;Cole et al., 1999;McAllister and Dyck, 2017;Nakashima and Dyck, 2009;Palmiter et al., 1996). Vesicular zinc inhibits activation of NMDA receptors that contain the GluN2A subunit (Paoletti et al., 1997;Paoletti et al., 2009), while it facilitates activation of non-NMDA receptors (reviewed in 
McAllister and Dyck, 2017;Ugarte and Osborne, 2001). GABA receptors are also modulated by zinc (Huang et al., 1993; Kawahara et al., 1993;Strecker et al., 1999). Zinc has also been shown to be the primary endogenous ligand for GPR39, a metabotropic receptor expressed in the brain that signals through the Gq-PLC-IP3 pathway (Besser et al., 2009).

The possibility that zinc can modulate circadian rhythms is suggested by its presence in the ganglion cell layer of the retina (Redenti and Chappell, 2004). Zinc has been histochemically located in the ventrolateral portion of the rat SCN (Huang, et al., 1993). In dissociated SCN neurons, zinc enhances the potassium $\mathrm{I}_{\mathrm{A}}$ current (Huang, et al., 1993), inhibits GABA $\mathrm{A}_{\mathrm{A}}$ currents (Kawahara, et al., 1993;Strecker, et al., 1999), and inhibits NMDA GluNR2A currents (Clark and Kofuji, 2010). These in vitro findings suggest that zinc could modulate circadian responses. To explore this possibility more fully, we devised a series of anatomical and behavioral studies to determine if vesicular zinc might modulate circadian rhythms. Using hamsters and mice, we explore the localization of vesicular zinc and its transporter ZnT3 in the retina and circadian network. We explore the effects that chelating or enhancing zinc levels in the SCN and IGL has on circadian responses to light. Finally, we explore the circadian properties of the ZnT3knockout (KO) mouse.

\section{EXPERIMENTAL PROCEDURES}

\section{Animals and housing}

Male C57BL/6J wildtype adult mice $(n=4)$ from an in-house colony were used for retinal ZnT3 and melanopsin immunohistochemistry. Syrian hamsters $(\mathrm{n}=40)$ obtained from Charles River Laboratories (Kingston, NY, USA) were used for sodium selenite injections and the vesicular zinc staining, enucleation, and photic entrainment experiments (detailed below). ZnT3- 
KO mice (n=9; B6;129-Slc30a3 $\left.3^{\text {tmlRpa }}\right)$ and wildtype littermate controls $(\mathrm{n}=9)$ were bred from heterozygous animals from an in-house colony founded by animals received from Dr. Richard Palmiter, University of Washington. ZnT3-KO mice were genotyped using the protocol for this strain provided by The Jackson Laboratory (https://www.jax.org/strain/005064) as previously described (Cole et al., 1999;Nakashima et al., 2011).

Animals were initially housed in pairs in a temperature and humidity-controlled room with either a 14:10 (hamsters) or 12:12 (mice) light-dark cycle (LD; approximately 1500 lux during the light phase) and provided with food and water ad libitum. Animals used in behavioural experiments were transferred to individual polycarbonate cages equipped with a running wheel. Periodic cage changes took place seven days prior and following manipulation days. The wheel running activity of the animals was recorded by means of a magnetic switch fastened to each wheel and monitored using Clocklab (Actimetrics, Wilmette, IL). All experiments adhered to the guidelines of the Canadian Council on Animal Care and were approved by the Life and Environmental Sciences Animal Care Committee at the University of Calgary.

\section{Surgery}

Some hamsters were surgically implanted with cannulas aimed at the SCN (unilateral, $\mathrm{n}=12$ ) or the IGL (bilateral, $\mathrm{n}=14$ ). Each animal received a subcutaneous injection of the analgesic butorphanol (2 mg/kg; Wyeth, Madison, NJ, USA) and an i.p. injection of the anesthetic sodium pentobarbital (90 mg/kg; CEVA). While under anesthesia, hamsters were stereotaxically implanted with either one (SCN) or two (IGL) $9 \mathrm{~mm}$ 22-gauge stainless steel cannulae (Plastics One Inc., Roanoke, VA, USA). The cannulae were cemented to the skull using dental acrylic and jeweler's screws. Coordinates for the SCN were $0.0 \mathrm{~mm}$ anterior to bregma, 
$0.3 \mathrm{~mm}$ lateral to the midline, $7.0 \mathrm{~mm}$ ventral to the skull surface, and coordinates for the IGL were $1.9 \mathrm{~mm}$ posterior to bregma and $3.3 \mathrm{~mm}$ lateral to the midline. To determine depth, two targets were calculated at $3.3 \mathrm{~mm}$ and $4.8 \mathrm{~mm}$ below dura and the skull, respectively. The average of the two target values was taken as the dorsoventral coordinate. The incisor bar was set to $2 \mathrm{~mm}$ below the interaural level for all surgeries. A dummy cannula was inserted to maintain patency.

Brains were collected for histology at the end of the experiment using the perfusion method described above. Brain sections were stained using cresyl violet and coverslipped in Permount. Animals were excluded if the tip of the cannula was more than $600 \mu \mathrm{m}$ away from the margin of the SCN, or if the tip of either one of the two cannulae was more than $600 \mu \mathrm{m}$ away from the margin of either IGL.

Some hamsters received bilateral enucleations. Hamsters were anesthetized with sodium pentobarbital (100-120 mg/kg) and provided with butorphanol as a pre-operative analgesic and given a subcutaneous injection of $0.5 \%$ bupivacaine into the area immediately around eye. When unconscious, the eye was gently dissected, and the optic nerve severed. Post-operative analgesic (butorphanol) was administered as needed.

\section{Histology}

\section{Autometallographic Zinc Staining}

The autometallographic zinc staining procedure was adapted from the technique previously employed by (Danscher, 1982). Hamsters received an i.p. injection of $15 \mathrm{mg} / \mathrm{kg}$ of sodium selenite dissolved in molecular grade water in DD conditions with the aid of night vision goggles (BG15Alista, Richmond Hill, Ontario, Canada) at either ZT6 or ZT18. One hour later, animals were euthanized with an overdose of sodium pentobarbital (250mg/kg Euthanyl). For 
experiments where the tissue was only being processed for autometallographic zinc staining, brains were rapidly extracted and immediately frozen on dry ice. If alternate sections were being processed using immunohistochemistry, animals were perfused transcardially with $\sim 50 \mathrm{ml}$ of cold phosphate buffered saline (PBS) followed by $50 \mathrm{ml}$ of cold $4 \%$ paraformaldehyde (PFA) in PBS. Frozen brain sections $(35 \mu \mathrm{m})$ were collected through the SCN and IGL with a cryostat and were mounted directly onto gelatin-coated microscope slides.

The tissue was allowed to thaw at room temperature and was then rehydrated in an alcohol series (95\% EtOH for $15 \mathrm{~min}, 70 \%$ for $2 \mathrm{~min}, 50 \%$ for $2 \mathrm{~min}, 3 \times 2 \mathrm{~min}$ in $\mathrm{dH} 2 \mathrm{O}$ ). Slides were then dipped in gelatin and transferred to a silver lactate solution for physical development. The developer solution was prepared by mixing the following solutions in order: $50 \%$ gum arabic from African Acacia trees (100 g in $200 \mathrm{ml} \mathrm{dH2O}$ ), citrate buffer (5.1g citric acid, $4.7 \mathrm{~g}$ sodium citrate, $20 \mathrm{ml} \mathrm{dH} 2 \mathrm{O})$, silver lactate $(0.22 \mathrm{~g}$ in $30 \mathrm{ml} \mathrm{dH} 2 \mathrm{O})$, and hydroquinone $(1.7 \mathrm{~g}$ in 20 $\mathrm{ml} \mathrm{dH2O).} \mathrm{Slides} \mathrm{were} \mathrm{developed} \mathrm{for} \mathrm{120-150} \mathrm{min} \mathrm{in} \mathrm{the} \mathrm{dark} \mathrm{and} \mathrm{were} \mathrm{checked} \mathrm{every} \mathrm{10-15}$ min, starting at $100 \mathrm{~min}$. Slides were removed from the developer solution after the tissue had obtained a dark brown uniform stain. The slides were then gently washed under slowly running tap water at $37^{\circ} \mathrm{C}$ for $10 \mathrm{~min}$ and then in $\mathrm{dH} 2 \mathrm{O}(2 \times 3 \mathrm{~min})$. Slides were then exposed to $5 \%$ sodium thiosulfate in $\mathrm{dH} 2 \mathrm{O}$ for $12 \mathrm{~min}$ and washed in $\mathrm{dH} 2 \mathrm{O}(2 \times 2 \mathrm{~min})$. Sections underwent a final alcohol dehydration series, were cleared with xylene and coverslipped with Permount. Immunohistochemistry

Immunohistochemistry protocols were adapted from those previously used in our lab (Smith et al., 2010). Animals received an overdose of sodium pentobarbital (Euthanyl, $250 \mathrm{mg} / \mathrm{kg}$ ) and were then transcardially perfused with cold PBS followed by cold $4 \%$ PFA in PBS. Depending on the experiment, brains or eyes were extracted and were post-fixed overnight 
at $4{ }^{\circ} \mathrm{C}$ in $4 \%$ PFA followed by $24 \mathrm{~h}$ in $20 \%$ sucrose in PBS. Frozen sagittal sections $(20 \mu \mathrm{m}$ for eyes, $35 \mu \mathrm{m}$ for brains) were collected with a cryostat and were mounted on gelatin-coated slides (eyes) or were collected into PBS baths (brains). The general immunohistochemistry procedure involved three 10 min washes in $0.3 \%$ PBS with Triton-X-100 (PBSx), followed by a 60-min incubation in blocking buffer (10\% normal donkey serum for immunofluorescence, $10 \%$ normal goat serum for diaminobenzidine (DAB) staining). Following this, the tissue was incubated in the primary antibodies for $48 \mathrm{~h}$ at $4^{\circ} \mathrm{C}$. Tissue was then rinsed again (six 10-min washes) before being incubated in the secondary antibodies. For tissue to be stained with DAB, the tissue was then incubated in an avidin-biotin complex bath (Vectastain elite, Vector Laboratories, Burlingame, CA). The tissue was then developed for approximately 5 min with $0.05 \%$ DAB and $0.02 \% \mathrm{NiCl}$ in $0.1 \mathrm{M}$ Tris buffer activated with $80 \mu \mathrm{L}$ of $30 \% \mathrm{H}_{2} \mathrm{O}_{2}$. Brain slices were dehydrated through an alcohol series, cleared with xylenes and coverslipped with Permount (Fisher Scientific, Ottawa, ON, USA) for DAB tissue, or with Krystalon for immunofluorescent tissue.

Retinal immunohistochemistry included a 20 min wash in 4\% PFA prior to initiation of the protocol detailed above. Primary antibodies used were for melanopsin (anti-rabbit 1:5000, Advanced Targeting Systems, San Diego, CA, USA) and ZnT3 (anti-mouse 1:800, Synaptic Systems, Goettingren, Germany). Secondary antibodies were CY-3 donkey anti-rabbit and CY-2 donkey anti-mouse (1:200, Jackson ImmunoResearch Laboratories Inc. West Grove, PA, USA).

Neuropeptide Y immunohistochemistry included a 30 min incubation in $0.5 \% \mathrm{H}_{2} \mathrm{O}_{2}$ prior to initiation of the protocol detailed above. The primary antibody was rabbit anti-NPY (1:10,000; ImmunoStar, Hudson, WI, USA), and a goat-anti rabbit biotinylated secondary was employed (1:200; Vector Laboratories, Burlingame, CA, USA). 
Mouse SCN immunohistochemistry used the follow primary antibodies: Fos (goat antiFos; 1:20,000; Santa Cruz Biotechnology, Santa Cruz, CA, USA), vasopressin (VP; guinea-pig anti-VP; 1:5000; Peninsula Laboratories, San Carlos, CA, USA), and bombesin/gastrin-releasing peptide (GRP; rabbit anti-GRP; 1:5000; ImmunoStar Inc., Hudson, WI, USA). The secondary antibodies used were CY-2 donkey anti-rabbit, CY-3 donkey anti-goat, and CY-5 donkey antiguinea-pig (all 1:200; Jackson ImmunoResearch Laboratories Inc., West Grove, PA, USA). $\underline{\text { In situ hybridization }}$

In situ hybridization followed our previously described protocol (Smith et al., 2008). Briefly, tissue was first treated with proteinase $\mathrm{K}(1 \mathrm{mg} / \mathrm{ml}, 0.1 \mathrm{M}$ Tris buffer $\mathrm{pH} 8.0,50 \mathrm{mM}$ EDTA; $10 \mathrm{~min})$ at $37^{\circ} \mathrm{C}$. This reaction was terminated with the addition of $4 \%$ PFA. Tissue was rinsed in saline sodium citrate $(300 \mathrm{mM} \mathrm{NaCl}, 30 \mathrm{mM}$ sodium citrate), and then treated with $0.25 \%$ acetic anhydride in $0.1 \mathrm{M}$ triethanolamine for $10 \mathrm{~min}$. The tissue was then incubated in 1.5 $\mathrm{ml}$ hybridization buffer (50\% formamide, $60 \mathrm{mM}$ sodium citrate, $600 \mathrm{mM} \mathrm{NaCl}, 10 \%$ dextran sulphate, $1 \%$ N-laurylsarcosine, $25 \mathrm{mg} / \mathrm{ml}$ tRNA, 1x Denhardt's, $0.25 \mathrm{mg} / \mathrm{ml}$ salmon sperm DNA) which also contained the DIG-labelled sense and antisense mPerl (mPer1 plasmid generously provided by Dr. L. Yan, Michigan State University, East Lansing, MI, USA) probes for $16 \mathrm{~h}$ at $60^{\circ} \mathrm{C}$. Following high-stringency post-hybridization washes (50\% formamide/saline sodium citrate at $60^{\circ} \mathrm{C}, 2 \times 30 \mathrm{~min}$ ), sections were treated with RNaseA, and then underwent more high-stringency washes. Tissue was then processed for immunodetection using a nucleic acid detection kit (Roche, Indianapolis, IN, USA). After incubation for $1 \mathrm{~h}$ at room temperature in $1.0 \%$ of blocking reagent in buffer one (100mM Tris-HCL buffer, $150 \mathrm{mM} \mathrm{NaCl,} \mathrm{pH} 7.5)$, sections were incubated in alkaline phosphatase-conjugated DIG antibodies diluted in buffer 1(1:5000) for 3 days at $4^{\circ} \mathrm{C}$. Sections were then washed in buffer $1(2 \times 15 \mathrm{~min})$ and incubated in 
buffer 3 (100 mM Tris-HCL buffer, $\mathrm{pH} 9.5$, containing $100 \mathrm{mM} \mathrm{NaCl}$ and $50 \mathrm{mM} \mathrm{MgCl}$ ) for 5 min and then incubated in a solution containing nitroblue tetrazolium salt $(0.34 \mathrm{mg} / \mathrm{ml})$ and 5bromo-4-chloro-3-indolyl phosphate toluidine salt $(0.18 \mathrm{mg} / \mathrm{ml})$ for $16 \mathrm{~h}$. The staining reaction was stopped by placing the sections in buffer 4 (10 mM Tris-HCL containing $1 \mathrm{mM}$ EDTA, pH 8.0). Tissue was then mounted on gelatin coated slides, air dried, dehydrated in an ascending alcohol series, cleared in xylene, air dried, and coverslipped with Permount. Image Analysis

All image analysis was performed on an Olympus BX51 microscope equipped for both brightfield and epifluorescence. Images were captured with a QI CAM Fast 1394 cooled CCD camera (QImaging, Burnaby, BC, Canada) connected to a computer running Image-Pro Plus software (Media Cybernetics, Inc. Rockville, MD).

Retinal histology: In total, 120 cells were identified. Colocalization was determined by initially identifying a melanopsin cell in the retinal ganglion cell layer (on the CY-3 filter channel) by its characteristic shape and extensive dendritic networks. The presence or absence of ZnT3 protein was then assessed. The signals were considered colocalized if the ZnT3 signal was of the same shape, size, and position as the initial melanopsin signal.

Zinc Histology: All images were captured with the same lighting conditions and exposure time. Densitometric analysis was completed on 16-bit images with the use of ImageJ software (ImageJ 1.42q; National Institutes of Health, Bethesda, MD). Zinc staining was quantified for the SCN by measuring the density of staining in each SCN nucleus and comparing the values to the density in the optic chiasm. The relative optical density (ROD) was calculated by taking the ratio of the SCN to optic chiasm density for the dorsolateral, dorsomedial and ventral regions. Density values were averaged across the SCN nuclei and ROD values were averaged across three 
consecutive SCN sections. ROD of IGL sections was determined by taking the ratio of staining in the IGL to staining in the dorsolateral geniculate nucleus (dLGN) for the left and right IGL. Representative rostral, mid and caudal IGL sections were averaged for the left and right IGL. Statistical significance was set at $p<0.05$ for all tests. Separate two-tailed independent samples ttests were conducted to analyze the ROD between the two time points for the dorsomedial, dorsolateral and ventral SCN, and the left and right IGL.

SCN histology: Tissues triple labelled for cFos, AVP, and GRP were captured. cFosimmunoreactive (-IR) cells were counted bilaterally at the mid-caudal level of the SCN. Cell counts were obtained in the SCN shell (delineated by AVP-IR cells) and in the SCN core (delineated by GRP-IR cells). Counts were conducted by two individuals blind to the treatment conditions. Images of DIG-labelled cells were captured using a RGB colour filter using the microscope described above. Measurements of ROD of staining were obtained bilaterally at the mid-caudal level of the SCN using ImageJ (ImageJ 1.34s; National Institutes of Health, Bethesda, MD, USA). The core and shell were analyzed separately by two individuals blind to the treatment conditions.

\section{Experiment 1- Confirming ZnT3 localization in ipRGCs}

We first explored if the ZnT3 zinc transporter was found in melanopsin-IR ganglion cells in the mouse retina. Mice $(n=4)$ were euthanized, perfused and their eyes were collected for double-label fluorescent immunohistochemistry as described above. Mouse tissue was used to explore this question as these antibodies did not produce specific staining in hamster retinas in our hands. We identified 120 melanopsin-IR cells. These were determined to be ZnT3-IR if signal on the ZnT3 channel had the same size, shape and location as the soma on the melanopsin channel. 


\section{Experiment 2- Histochemical zinc staining}

Eight male Syrian hamsters were used for visualization of histochemical zinc in the SCN and IGL. Two weeks prior to the beginning of the experiment, the animals were transferred to individual cages and kept under the same light-dark cycle. Two days prior to receiving sodium selenite injections, all animals were moved to constant dark (DD). Zinc terminal staining was visualized at two specific time points: the middle of the former light period (defined as zeitgeber time, ZT6) and the middle of the former dark period (ZT18), where lights off in the former LD cycle is designated ZT12 by convention (n=4 per group).

\section{Experiment 3- Does zinc input to the circadian system come from the retina?}

To test the hypothesis that the retina is the source of zinc input to the circadian system, six male hamsters (controls $n=3, n=3$ experimental animals) underwent a bilateral enucleation surgery as described above. As experiment \#2 revealed prominent staining in the IGL but only sparse staining in the SCN, we focused on the IGL in this experiment. A week of recovery was allowed to provide time for the degeneration of remaining retinal projections. Hamsters then received an i.p. injection of sodium selenite $(15 \mathrm{mg} / \mathrm{kg})$. An hour later, animals were euthanized with an overdose of sodium pentobarbital $(250 \mathrm{mg} / \mathrm{kg})$ and were then perfused transcardially with $\sim 50 \mathrm{ml}$ of cold PBS followed by 50ml of cold 4\% PFA in PBS. Brains were PFA fixed in this experiment to allow alternate sections to be stained for NPY to delineate the IGL. Sections were collected as described above, with one series being processed for zinc as described above. The alternate series was immunostained for NPY. Relative optical density was used to assess density of zincergic terminals in the IGL of both control and enucleated hamsters.

\section{Experiment 4- Effect of zinc level modulation on circadian responses to light}


To test the effects of manipulating zinc levels on circadian responses to light, male hamsters underwent cannula implantation surgery (SCN, n=12; IGL, n=14) as described above. Zinc chloride $\left(\mathrm{ZnCl}_{2}\right.$; Sigma) dissolved in $0.9 \%$ saline to a final concentration of $50 \mu \mathrm{M}$ was used to increase extracellular zinc (Takeda et al., 2003), while N,N, $\mathrm{N}^{\prime}, \mathrm{N}^{\prime}-$ Tetrakis(2pyridylmethyl)ethylenediamine (TPEN; Sigma) dissolved in 10\% dimethylsulfoxide (DMSO) to a final concentration of 5mM was used as a zinc chelator (Cuajungco and Lees, 1996). Vehicle controls of $0.9 \%$ sterile saline and $10 \%$ DMSO were included for the zinc donor and chelator, respectively. Drugs were administered to animals based on a counterbalanced design throughout the course of the experiment. Due to deterioration of rhythmicity with repeated SCN injections, only one vehicle control manipulation was performed on each animal (either saline or 10\%DMSO). Repeated IGL injections did not lead to the same deterioration of rhythmicity, so these animals received both vehicle treatments in addition to the $\mathrm{ZnCl}_{2}$ and TPEN treatments. Intracranial injections of $0.5 \mu \mathrm{L}$ of drugs were administered over a period of 30 seconds during each manipulation by means of a 26 -gauge injection cannula attached to a $1 \mu \mathrm{L}$ Hamilton syringe with polyethylene 20 tubing. The injection cannula extended $1 \mathrm{~mm}$ beyond the tip of the implanted guide cannula. All injections were made in DD conditions with the aid of night-vision goggles. Ten minutes following drug administration, animals were placed in light boxes and were exposed to a 15-min 40 lux light pulse in the late subjective night (circadian time (CT18, 6 $\mathrm{h}$ after activity onset, which is defined as CT12 by convention). Phase shifts were analyzed with Clocklab by fitting a regression line to activity onsets for the 10 days prior to the manipulation and another to onsets on days 3-10 following the manipulation. The horizontal difference between these lines on the day following the manipulation was used as the phase shift. 
All comparisons were made using SigmaPlot (Systat Software, Inc.; San Jose, CA). Statistical significance was set at $p<0.05$ for all tests. A one-way repeated measures ANOVA was used to determine whether there was a statistically significant difference in the photic phase shifts between the conditions (zinc donor, zinc chelator, vehicle control). For the SCN injections, animals only received one of the two vehicles (either saline or DMSO). A two-tailed independent samples t-test was used to compare phase shifts in these vehicle conditions, and they were merged for the sake of the ANOVA analysis if there was no difference between the vehicle treatment. For the IGL treatments, animals received both vehicle treatments. A two-tailed paired t-test was used to compare these shifts, and as they did not significantly differ, the average of these was used for the ANOVA analysis. All means are reported as \pm standard error of the mean (SEM) in the figures and as \pm standard deviation in the text.

\section{Experiment 5- Circadian rhythms changes in the ZnT3 KO model}

\section{$\underline{\text { Circadian Behavior }}$}

To explore the consequences of global loss of vesicular zinc on circadian rhythms, we used mice lacking ZnT3. These mice exhibit a complete lack of vesicular zinc in the brain (Cole, et al., 1999;McAllister and Dyck, 2017). Mice were initially housed in an LD cycle. After two weeks in LD, the mice underwent a masking paradigm, whereby for $24 \mathrm{~h}$, the LD cycle was 2:2. Mice were then returned to LD for two more weeks before being transferred to DD. After two weeks in DD, the mice were exposed to a dim light pulse (15 min, 40 lux) at either CT16 (early night) or CT22 (late night). Two weeks later, the mice were exposed to a light pulse again, however this time undergoing the pulse at the other time. Following this, the same paradigm of light pulses was repeated; however, in the second round, bright light ( 1200 lux) was used. Two 
weeks following this manipulation, animals were exposed to a bright light pulse ( 1200 lux) during the subjective day (CT6).

Circadian analysis

Basic features of the circadian rhythms of the ZnT3-KO mice were quantified using mice running wheel data collected in Clocklab as previously described (Smith et al., 2015). The LD ratio, a comparison of the running of the mice during the day versus night, was determined. Mean group waveforms were constructed to examine differences in the duration of the active period and rest periods in LD and in DD (period and power values using Clocklab's Chi Square Periodogram). Period and power of the rhythms were assessed over three blocks in DD (Block one: DD days 1-10, Block two: DD days 48-57, and Block three: DD days 76-84). The difference between the onset of the main nocturnal bout of running and the time of lights off, also known as the phase angle of entrainment (psi), was determined at two points during LD. The duration of the active phase (alpha) and amount of activity, were calculated for the same two points during LD, as well as one point during DD. The effect of masking was determined by compiling the information gathered from the 24 hours the mice spent in the $2: 2$ LD cycle into 2hour light and dark periods and then calculating a LD ratio. Additionally, LD ratios were calculated from the masking data by averaging values based on the day and night of the original 12:12 LD cycle. Phase shifts were calculated following exposure to dim ( 40 lux) or bright light ( 1250 lux) at CT16 or CT22 and after exposure to bright light at CT6. Phase shifts were calculated as was described in Experiment 4.

$\underline{\text { Light induced cFos and mPerl expression }}$

Two weeks after the completion of the third round of light pulses, cFos and mPerl expression following a 15-min bright light pulse was assessed at either CT16 or CT22 in both 
WT and KO mice ( $\mathrm{n}=3$ each genotype and phase). Ninety minutes after exposure to the light pulse, animals were euthanized, in the dark, via an overdose of sodium pentobarbital, and then perfused as described above. Gene expression was also assessed for a second group of WT and KO mice ( $\mathrm{n}=3$ each) when administered a bright light pulse at CT22. Image quantification and statistics

Behavioural data for LD ratios, alpha, and psi were analyzed by comparing measures obtained for KO mice with that of WTs. Independent samples t-tests were utilized with significance set at $p<0.05$. Violations of the assumption of homogeneity of variance were assessed using Levene's test. For power and period data, the effect of time was assessed by using 2x3 mixed factorial ANOVA (genotype: WT, KO x time: block 1, 2, and 3) statistical tests. Phase shifts were analyzed using a 2x2x2 mixed ANOVA (genotype: WT, KO x light: dim, bright x phase: CT16, CT22) with light and phase being the within-subjects factors and genotype the between-subjects factor. As only a bright light pulse was used at the CT6 phase, it was considered in isolation and assessed using an independent samples t-test. In order to compare the expression of the FOS protein and mPerl gene in the core versus the shell, 2x2x2 (genotype:

WT, KO x phase: CT16, CT22 x region: core, shell) factorial mixed ANOVAs were conducted. Region was the within-subjects factor while genotype and phase were the between-subjects factor. Statistical significance was set at $p<0.05$. All means are reported \pm SD in the text and \pm SEM in figures.

\section{RESULTS}

\section{Experiment 1: ZnT3 colocalization with melanopsin retinal ganglion cells}

A subset of ipRGCs that contain ZnT3 project to the circadian system (Figure 1). Images of positive staining for melanopsin show the entire ipRGC cell with its large cell body and 
extensive dendritic arbor visible in the ganglion cell layer. Positive ZnT3 staining was identified as a speckle formation outlining a cell along its perimeter. From a total of $120 \mathrm{ipRGCs,} 47.5 \%$ were identified as melanopsin single-labelled cells while $52.5 \%$ were identified as melanopsin ZnT3 double-labelled cells.

\section{Experiment 2: Histochemical zinc expression in the SCN and IGL}

A small amount of vesicular zinc staining was present throughout the SCN, which was mostly visible in rostral sections, in the medial and ventral regions (Figure 2A-C). Quantification took place on seven brains, with one animal excluded due to the inability to obtain representative sections. There was no significant difference in vesicular zinc levels (as measured by ROD) between the two time points, ZT6 and ZT18, for the dorsomedial $\left(t_{(5)}=1.879, p>0.05\right)$, dorsolateral $\left(t_{(5)}=1.634, p>0.05\right)$ or ventral $\left(t_{(5)}=0.875, p>0.05\right) \mathrm{SCN}$ areas (Figure 3A,B). In contrast, a considerable amount of vesicular zinc was present throughout the full rostrocaudal extent of the IGL and extending lower down in the ventrolateral geniculate nucleus (vLGN;

Figure 2D-O). Vesicular zinc levels did not significantly differ between ZT6 and ZT18 ( $t_{(5)}$ $=1.518, p>0.05$, Figure 3C,D).

\section{Experiment 3: Vesicular zinc is present in the IGL with or without retinal input}

NPY staining was used to delineate the IGL in adjacent sections. Histochemically stained zinc was observed in control animals as well as enucleated animals and there was no significant difference in vesicular zinc staining in the IGL between these two groups $\left(t_{(4)}=1.741, p>0.05\right.$; Figure 4).

Experiment 4: Zinc level modification at the SCN and IGL does not alter circadian responses to light 
All 12 animals were used for analysis for SCN treatments. Data from a total of eight hamsters were used in the analysis for IGL treatments. Histological examination led to three animals being excluded due to missed placements for one of the two cannulas aimed at the left or right IGL. Another animal was excluded after losing its headcap during the first manipulation. Two more animals were excluded due to near zero phase shifts following light exposure in the vehicle control condition. No animals were excluded based on responses to experimental treatments.

Light-induced phase shifts did not differ significantly between the two vehicle treatment conditions of saline and DMSO for either the intra-SCN treatment (saline: $1.820 \pm 0.258 \mathrm{~h}$;

DMSO: $1.686 \pm 0.326 \mathrm{~h}$; independent t-test, $\left.t_{(10)}=0.326, p=0.751\right)$ or the intra-IGL treatments (saline: 1.854 $\pm 0.640 \mathrm{~h}$; DMSO: $1.924 \pm 0.722 \mathrm{~h}$; paired t-test, $t_{(12)}=0.192, p=0.851$ ). As a result, the saline and DMSO data was combined into one vehicle group in these experiments for further analysis with the active treatment conditions (i.e., vs $\mathrm{ZnCl}_{2}$ and TPEN conditions). For intraSCN treatments (Figure 5), there was no significant difference $\left(F_{(11,22)}=0.926, p=0.411\right)$ in phase shifts between the vehicle (1.764 $\pm 0.194 \mathrm{~h}), \mathrm{ZnCl}_{2}(2.007 \pm 0.239 \mathrm{~h})$, or TPEN $(1.669 \pm 0.193 \mathrm{~h})$. Similarly for the intra-IGL experiment, there were no significant differences $\left(F_{(7,13)}=0.752\right.$, $p=0.491)$ in phase shifts between the vehicle $(1.843 \pm 0.432 \mathrm{~h}), \mathrm{ZnCl}_{2}(1.619 \pm 0.743 \mathrm{~h})$, or TPEN $(1.571 \pm 0.8 \mathrm{~h})$ treatments (Figure 6).

\section{Experiment 5: Circadian rhythms changes in the ZnT3 KO model}

General circadian characteristics.

In a light-dark cycle, ZnT3-KO mice exhibited circadian patterns of wheel running behavior that were similar to wildtype controls. Actograms and average waveforms for the genotypes were of similar appearance (Figure 7). Both genotypes exhibited pronounced 
nocturnal behavior with limited activity during the light phase. The L/D ratios (i.e., activity in light phase / activity in the dark phase) were not significantly different between the genotypes (WT: $0.029 \pm 0.022 ; \mathrm{KO}: 0.036 \pm 0.028 ; t_{(10)}=0.474, p=0.646$ ). The duration of the active phase (alpha) was similar between the genotypes (LD: WT $=6.35 \pm 0.8 \mathrm{~h}, \mathrm{KO}=5.8 \pm 1.0 \mathrm{~h} ; t_{(10)}=1.02$, $p=0.331$; DD: WT=6.6 $\left.\pm 1.0 \mathrm{~h}, \mathrm{KO}=5.8 \pm 1.59 \mathrm{~h}, t_{(10)}=1.046, p=0.320\right)$. Both wildtype and ZnT3KO mice exhibited small positive phase-angles of entrainment (WT: $6.4 \pm 0.8 \mathrm{~min}, \mathrm{KO}: 5.8 \pm 1.0$ $\min )$ that were not significantly different $\left(t_{(10)}=1.02, p=.331\right)$.

In constant darkness, both WT and KO mice exhibited clear free-running rhythms (Figure 8) that did not significantly differ in terms of their period (WT=23.67 $\pm 0.1 \mathrm{~h}, \mathrm{KO}=23.64 \pm 0.2 \mathrm{~h}$; $\left.F_{(1,10)}=0.090, p=0.770\right)$ or their power $\left(\mathrm{Max} \chi^{2}\right.$ power: $\mathrm{WT}=716.19 \pm 228.19, \mathrm{KO}=771.73 \pm 260.62$; $F_{(1,10)}=0.586, p=0.462$ ). Period and power significantly decreased with time in DD (main effect of block for both period, $F_{(2,10)}=15.06, p<0.001$, and power, $\left.F_{(2,10)}=31.32, p<0.001\right)$, but this change was similar for both genotypes (genotype $\mathrm{X}$ block interaction for period, $F_{(2,10)}=0.595$, $p=0.561$, and power, $\left.F_{(2,10)}=0.015, p=0.985\right)$.

\section{Masking}

For the masking paradigm, LD ratios (see above) were calculated for activity that occurred during the $12 \mathrm{~h}$ day, $12 \mathrm{~h}$ night, and the full $24 \mathrm{~h}$ period when animals were housed in a LD 2:2 cycle. During the day, the ratio of activity when the lights were on compared to when the lights were off was not significantly different between the WT mice $(0.038 \pm 0.026)$ and KO mice $\left(0.252 \pm 0.430 ; t_{(10)}=1.22, p=0.251\right)$. Similarly, during the night, LD ratios were not significantly different between WT mice $(0.060 \pm 0.030)$, and KO mice $\left(0.098 \pm 0.106 ; t_{(10)}=0.842, p=0.419\right)$. Total LD ratios were also not significantly different between WT $(0.058 \pm 0.028)$ and KO mice $\left(0.100 \pm 0.101 ; t_{(10)}=0.975, p=0.352\right)$. 


\section{$\underline{\text { Phase shifts }}$}

Phase shifts were examined following exposure to dim (40lux) and bright (1250lux) light at CT16 and CT22, as well as following exposure to bright light at CT6. Representative phase shifts to the bright light at CT16 and CT22 are displayed in Figure 9. Large phase delays and advances were observed to light pulses at CT16 and CT22 respectively. At both CT16 and CT22 phase shifts were significantly larger with bright light exposure $\left(\mathrm{CT} 16 F_{(1,10)}=5.384, p=0.043\right.$; CT22 $\left.F_{(1,10)}=28.884, p<0.001\right)$. In neither case were the phase shifts significantly different between the genotypes $\left(\mathrm{CT} 16 F_{(1,10)}=0.552, p=0.475\right.$; CT22 $\left.F_{(1,10)}=0.271, p=0.614\right)$. There were no significant interactions between genotype and light intensity $\left(\mathrm{CT} 16 F_{(1,10)}=0.00176, p=0.967\right.$; CT22 $\left.F_{(1,10)}=0.325, p=0.581\right)$. Small phase delays were observed to bright light pulses at CT6 but did not significantly differ between the genotypes (WT $-0.37 \pm 0.532 \mathrm{~h}, \mathrm{KO}-0.578 \pm 0.385$, $\left.t_{(9)}=0.762, p=0.466\right)$.

\section{$\underline{\text { Light-Induced Gene Expression }}$}

Light pulses (15min, 1250lux) induced prominent Fos expression in the SCN (Figure 9). Regardless of phase or genotype, greater FOS expression was observed in the SCN core than in the $\operatorname{SCN}$ shell $\left(F_{(1,8)}=148.87, p<0.001\right)$. None of the interactions involving region were significant (phase: $F_{(1,8)}=0.611, p=.457$; genotype: $F_{(1,8)}=0.296, p=0.601$; phase $\mathrm{x}$ genotype: $\left.F_{(1,8)}=0.235, p=0.651\right)$. Additionally, no significant differences in FOS expression were observed in relation to phase $\left(F_{(1,8)}=1.09, p=0.326\right)$ or genotype $\left(F_{(1,8)}=0.007, p=0.933\right)$. The interaction between phase and genotype was also not significant $\left(F_{(1,8)}=0.002, p=0.964\right)$.

Light pulses also induced prominent mPerl expression in the SCN (Figure 9). Regardless of phase or genotype, greater mPerl expression was observed in the SCN core than in the SCN shell $\left(F_{(1,14)}=89.88, p<0.001\right)$. No significant differences in $m P e r 1$ expression were observed in 
relation to phase $\left(F_{(1,14)}=0.191, p=0.668\right)$ or genotype $\left(F_{(1,14)}=0.075, p=0.789\right)$. The interaction between region and phase was not significant $\left(F_{(1,14)}=0.007, p=0.932\right)$ nor was the interaction between region and genotype, $F_{(1,14)}=0.349, p=0.564$. The three-way interaction between region, phase, and genotype was also not significant, $F_{(1,14)}=1.40, p=0.256$.

\section{DISCUSSION}

The present study is the first to thoroughly examine the anatomical distribution and functional role of vesicular zinc in the circadian system. Consistent with previous reports (Redenti and Chappell, 2004), we localized the vesicular zinc transporter ZnT3 to the ganglion cell layer of the retina, and demonstrated that a subset of melanopsin-containing ipRGCs colocalized ZnT3. Minimal vesicular zinc was observed in the hamster SCN, contrasting with previous reports that detected zinc in the rat SCN (Huang, et al., 1993). However, strong histochemically-stained zinc was detected throughout the entire IGL structure. Vesicular zinc staining was also observed throughout the ventrolateral geniculate. Zinc staining levels in the SCN and IGL did not change across the circadian day. While retinal ganglion cells project to the lateral geniculate and IGL, loss of the eyes did not significantly alter vesicular zinc staining in these structures, suggesting that they receive significant zinc input from elsewhere in addition to or instead of from the retina. While some ipRGCs were found to colocalize ZnT3, allowing them to synaptically release zinc, increasing or decreasing zinc in either the SCN or IGL failed to significantly alter circadian responses to phase shifting light pulses in hamsters. Similarly, mice lacking ZnT3 which have no vesicular zinc, did not exhibit any differences from wildtype mice in entrained, free-running or phase shifting circadian responses. It is possible that other circadian tasks, such as anticipation of scheduled feeding, or other non-photic manipulations, might reveal a difference between the WT and ZnT3 mice. 
The colocalization of ZnT3 with ipRGCs suggest a possible function of vesicular zinc as a modulator in the brain areas innervated by ipRGCs. A number of ipRGC subtypes have been noted, with distinct morphologies and projection patterns (Berson et al., 2010; Sexton et al., 2012;Schmidt et al., 2011). Specifically, the M1 type lacking BRN3b project to the SCN while the M2 type that contains BRN3b project to the IGL. Many of the melanopsin-positive cells that were observed to contain ZnT3 had their dendrite more in the ON sublamina of the inner plexiform layer, suggesting that these were M2, M3, M4 or M5 ipRGCs, which project to structures such as the dorsolateral geniculate, the superior colliculus, or the core of the olivary pretectal nucleus (Schmidt et al., 2011). The lack of change of zinc staining in the IGL and vLGN of enucleated hamsters does not exclude the possibility that the retina provides zincergic input, but at a minimum requires that there also be other significant sources of vesicular zinc input. The IGL receives considerable afferent projections from several different brain areas including visual centers such as the superior colliculus (SC), visual cortex and dLGN (Moore et al., 2000), the hypothalamus, and the raphe nucleus. Of these, the visual cortex is known to contain zincergic neurons (Brown and Dyck, 2004). While manipulations of zinc levels in the hamster IGL, or globally with the ZnT3-KO mouse failed to alter circadian responses to light, the IGL is also known to participate in non-photic phase shifting (Webb et al., 2014). It is possible that zinc may play a role in regulating these non-photic responses. Photic stimuli interfere with non-photic responses (Mrosovsky, 1991) so it is possible that zincergic input to the IGL might modulate this phenomenon.

Vesicular zinc is found in high levels in the retina, largely in the photoreceptor cells, amacrine cells, and retinal pigment epithelial cells (Ugarte and Osborne, 2001). The location of vesicular zinc in photoreceptors changes with the light cycle, but this appears to be a light- 
regulated rather than a circadian-regulated feature (Ugarte and Osborne, 2001). In the retina, vesicular zinc may play a number of roles. ZnT3 is found in a number of retinal cells (Redenti and Chappell, 2004), and synaptically-released zinc appears to modulate NMDA and GABA receptors in a number of retinal circuits (Ripps and Chappell, 2014;Ugarte and Osborne, 2001). Zinc also regulates the activity of retinol dehydrogenase necessary for the production of retinal. This latter role is thought to explain night-blindness and poor dark adaptation in people with zinc deficiencies (Ugarte and Osborne, 2001). Patients with zinc deficiencies take longer to adapt to darkness and are less sensitive when fully adapted (Morrison et al., 1978). Circadian responses to light are influenced by dark adaptation, with responses to light increasing with time in constant darkness (Daymude and Refinetti, 1999;Refinetti, 2001;Shimomura and Menaker, 1994). However, the timescale for maximal dark adaptation of circadian responses, about 3 weeks, far exceeds the timescale for dark adaptation of visual responses in people ( 40 min;Pirenne, 1962). Given the lack of difference in phase shifts between WT and ZnT3-KO mice, it is likely that if vesicular zinc plays a role in dark adaptation of the circadian response, then this many be mediated by free zinc rather than synaptically-released zinc that requires the ZnT3 transporter.

A role for vesicular zinc in the SCN has been suggested previously (Huang, et al., 1993). In rats, using a technique similar to that employed here, those authors detected prominent zincergic input to the ventral region of the SCN. It was found that zinc enhanced inhibitory outward potassium $\mathrm{I}_{\mathrm{A}}$ currents in isolated SCN neurons from the rat (Huang, et al., 1993). $\mathrm{GABA}_{\mathrm{A}}$ currents are also zinc sensitive in the rat SCN (Kawahara, et al., 1993;Strecker, et al., 1999). The sensitivity of these GABA-induced current to zinc varies over the day (Kretschmannova et al., 2005;Kretschmannova et al., 2003). Finally, NMDA currents in the SCN are also inhibited in vitro by zinc, an observation which has been used as evidence of the 
presence of the zinc-sensitive GluN2A subunit of the NMDA receptor (Clark and Kofuji, 2010).

The lack of responses to manipulations of zinc in our study could reflect species differences between rats used in these other studies and hamsters and mice explored here. Alternatively, the pharmacological responses observed in vitro in these other studies may not translate to the intact behaving animals explored here.

The transgenic mouse model used here has lacked the ZnT3 transporter since fertilization, thus there may be developmental compensation to mitigate the persistent lack of vesicular zinc. Similar to what we observed with our circadian investigations, ZnT3 mice do not differ from WT mice on a wide variety of behavioural tasks (Cole et al., 2001). Recent evidence suggest that differences do start to emerge when tasks are designed to be especially sensitive/challenging, or when the animals are subjected to stress (McAllister et al., 2018; Thackray et al., 2017;Wu and Dyck, 2018).

Zinc is a critical essential trace element that participates in a wide variety of biochemical processes. With the present study, we have found that the transporter responsible for packaging zinc into synaptic vesicles is located in a subset of melanopsin-containing ipRGCs, and that vesicular zinc is found throughout the IGL. Despite this, altering zinc levels in the circadian system with zinc donors or chelators did not alter circadian responses to light, and genetic deletion of the necessary transporter for packaging of vesicular zinc did not alter any of the entrained, free-running or phase shifting circadian responses. While our study provides evidence for the presence of vesicular zinc in the wider circadian network (i.e., retina and IGL), our current approaches failed to find a functional role for vesicular zinc in the circadian system. 


\section{REFERENCES}

Antle MC, Ogilvie MD, Pickard GE, Mistlberger RE (2003) Response of the mouse circadian system to serotonin 1A/2/7 agonists in vivo: Surprisingly little. J Biol Rhythms 18:145158.

Antle MC, Silver R (2005) Orchestrating time: Arrrangements of the brain circadian clock. Trends Neurosci 28:145-151.

Berson DM, Castrucci AM, Provencio I (2010) Morphology and mosaics of melanopsinexpressing retinal ganglion cell types in mice. J Comp Neurol 518:2405-2422.

Berson DM, Dunn FA, Takao M (2002) Phototransduction by retinal ganglion cells that set the circadian clock. Science 295:1070-1072.

Besser L, Chorin E, Sekler I, Silverman WF, Atkin S, Russell JT, Hershfinkel M (2009) Synaptically released zinc triggers metabotropic signaling via a zinc-sensing receptor in the hippocampus. J Neurosci 29:2890-2901.

Biello SM, Golombek DA, Harrington ME (1997) Neuropeptide Y and glutamate block each other's phase shifts in the suprachiasmatic nucleus in vitro. Neuroscience 77:1049-1057.

Brown CE, Dyck RH (2004) Distribution of zincergic neurons in the mouse forebrain. J Comp Neurol 479:156-167.

Clark JP, Kofuji P (2010) Stoichiometry of N-methyl-D-aspartate receptors within the suprachiasmatic nucleus. J Neurophysiol 103:3448-3464.

Cole TB, Martyanova A, Palmiter RD (2001) Removing zinc from synaptic vesicles does not impair spatial learning, memory, or sensorimotor functions in the mouse. Brain Res $891: 253-265$. 
Cole TB, Wenzel HJ, Kafer KE, Schwartzkroin PA, Palmiter RD (1999) Elimination of zinc from synaptic vesicles in the intact mouse brain by disruption of the ZnT3 gene. Proc Nat Acad Sci USA 96:1716-1721.

Cuajungco MP, Lees GJ (1996) Prevention of zinc neurotoxicity in vivo by N,N,N',N-tetrakis(2pyridylmethyl) ethylenediamine (TPEN). Neuroreport 7:1301-1304.

Danscher G (1982) Exogenous selenium in the brain: A histochemical technique for light and electron microscopical localization of catalytic selenium bonds. Histochemistry 76:281293.

Daymude JA, Refinetti R (1999) Phase-shifting effects of single and multiple light pulses in the golden hamsters. Biol Rhythm Res 30:202-215.

Ebling FJP (1996) The role of glutamate in the photic regulation of the suprachiasmatic nucleus. Prog Neurobiol 50:109-132.

Hattar S, Liao HW, Takao M, Berson DM, Yau KW (2002) Melanopsin-containing retinal ganglion cells: Architecture, projections, and intrinsic photosensitivity. Science 295:1065-1070.

Huang R-C, Peng Y-W, Yau K-W (1993) Zinc modulation of a transient potassium current and histochemical localization of the metal in neurons of the suprachiasmatic nucleus. Proc Nat Acad Sci USA 90:11806-11810.

Kawahara F, Saito H, Katsuki H (1993) Pharmacological characteristics of GABA responses in postnatal suprachiasmatic neurons in culture. Neurosci Lett 160:45-48.

Kretschmannova K, Svobodova I, Balik A, Mazna P, Zemkova H (2005) Circadian rhythmicity in AVP secretion and GABAergic synaptic transmission in the rat suprachiasmatic nucleus. Ann NY Acad Sci 1048:103-115. 
Kretschmannova K, Svobodova I, Zemkova H (2003) Day-night variations in zinc sensitivity of $\mathrm{GABA}_{\mathrm{A}}$ receptor-channels in rat suprachiasmatic nucleus. Mol Brain Res 120:46-51.

McAllister BB, Dyck RH (2017) Zinc transporter 3 (ZnT3) and vesicular zinc in central nervous system function. Neurosci Biobehav Rev 80:329-350.

McAllister BB, Wright DK, Wortman RC, Shultz SR, Dyck RH (2018) Elimination of vesicular zinc alters the behavioural and neuroanatomical effects of social defeat stress in mice. Neurobiol Stress 9:199-213.

Mistlberger RE, Antle MC (1998) Behavioral inhibition of light-induced circadian phase resetting is phase and serotonin dependent. Brain Res 786:31-38.

Moore RY, Speh JC, Card JP (1995) The retinohypothalamic tract originates from a distinct subset of retinal ganglion cells. J Comp Neurol 352:351-366.

Moore RY, Weis R, Moga MM (2000) Efferent projections of the intergeniculate leaflet and the ventral lateral geniculate nucleus in the rat. J Comp Neurol 420:398-418.

Morrison SA, Russell RM, Carney EA, Oaks EV (1978) Zinc deficiency: A cause of abnormal dark adaptation in cirrhotics. Am J Clin Nutr 31:276-281.

Mrosovsky N (1991) Double-pulse experiments with nonphotic and photic phase-shifting stimuli. J Biol Rhythms 6:167-179.

Nakashima AS, Butt RH, Dyck RH (2011) Alterations in protein and gene expression within the barrel cortices of ZnT3 knockout mice: Experience-independent and dependent changes. Neurochem Int 59:860-870.

Nakashima AS, Dyck RH (2009) Zinc and cortical plasticity. Brain Res Reviews 59:347-373. Palmiter RD, Cole TB, Quaife CJ, Findley SD (1996) ZnT-3, a putative transporter of zinc into synaptic vesicles. Proc Nat Acad Sci USA 93:14934-14939. 
Paoletti P, Ascher P, Neyton J (1997) High-affinity zinc inhibition of NMDA NR1-NR2A receptors. J Neurosci 17:5711-5725.

Paoletti P, Vergnano AM, Barbour B, Casado M (2009) Zinc at glutamatergic synapses. Neuroscience 158:126-136.

Pirenne MH (1962) Dark adaptation and night vision. In: The eye: The visual process, vol. 2 (Davson H, ed). London: Academic Press.

Provencio I, Rodriguez IR, Jiang G, Hayes WP, Moreira EF, Rollag MD (2000) A novel human opsin in the inner retina. J Neurosci 20:600-605.

Rea MA, Glass JD, Colwell CS (1994) Serotonin modulates photic responses in the hamster suprachiasmatic nuclei. J Neurosci 14:3635-3642.

Redenti S, Chappell RL (2004) Localization of zinc transporter-3 (ZnT-3) in mouse retina. Vision Res 44:3317-3321.

Refinetti R (2001) Dark adaptation in the circadian system of the mouse. Physiol Behav 74:1-15.

Ripps H, Chappell RL (2014) Review: Zinc's functional significance in the vertebrate retina. Mol Vision 20:1067-1074.

Rusak B, Zucker I (1979) Neural regulation of circadian rhythms. Physiol Rev 59:449-526.

Sexton T, Buhr E, Van Gelder RN (2012) Melanopsin and mechanisms of non-visual ocular photoreception. J Biol Chem 287:1649-1656.

Schmidt TM, Chen SK, Hattar S (2011) Intrinsically photosensitive retinal ganglion cells: Many subtypes, diverse functions. Trends Neurosc 34:572-580.

Shimomura K, Menaker M (1994) Light-induced phase shifts in tau mutant hamsters. J Biol Rhythms 9:97-110. 
Smith VM, Hagel K, Antle MC (2010) Serotonergic potentiation of photic phase shifts:

Examination of receptor contributions and early biochemical/molecular events.

Neuroscience 165:16-27.

Smith VM, Jeffers RT, McAllister BB, Basu P, Dyck RH, Antle MC (2015) Effects of lighting condition on circadian behavior in 5- $\mathrm{HT}_{1 \mathrm{~A}}$ receptor knockout mice. Physiol Behav 139: $136-144$.

Smith VM, Sterniczuk R, Phillips CI, Antle MC (2008) Altered photic and non-photic phase shifts in 5-HT(1A) receptor knockout mice. Neuroscience 157:513-523.

Strecker GJ, Park WK, Dudek FE (1999) Zinc and flunitrazepam modulation of GABA-mediated currents in rat suprachiasmatic nucleus. J Neurophysiol 81:184-191.

Takeda A, Minami A, Seki Y, Oku N (2003) Inhibitory function of zinc against excitation of hippocampal glutamatergic neurons. Epilepsy Res 57:169-174.

Thackray SE, McAllister BB, Dyck RH (2017) Behavioral characterization of female zinc transporter 3 (ZnT3) knockout mic. Behav Brain Res 321:36-49.

Ugarte M, Osborne NN (2001) Zinc in the retina. Prog Neurobiol 64:219-249.

Webb IC, Antle MC, Mistlberger RE (2014) Regulation of circadian rhythms in mammals by behavioral arousal. Behav Neurosci 128:304-325.

Wu HPP, Dyck RH (2018) Signaling by synaptic zinc is required for whisker-mediated, fine texture discrimination. Neuroscience 369:242-247. 


\section{Figure Captions}

Figure 1 Representative mouse retinal section showing immunofluorescent staining for ZnT3 (top row, green arrows) and melanopsin cells (middle row, red arrow) in the ganglion cell layer (GCL). The bottom row shows a merged image from which colocalization can be deciphered. Three single-labeled ZnT3-IR cells (green arrows) are evident, as is one double-labeled ZnT3+ melanopsin cell (yellow arrow). Scale bar $=30 \mu \mathrm{m}$.

Figure 2 Photomicrographs of representative hamster coronal slices showing autometallographic zinc staining in the suprachiasmatic nucleus (SCN; rostral to caudal direction A-C) and left intergeniculate leaflet (denoted by boxed area; rostral to caudal direction $\mathrm{D}$ to $\mathrm{O})$. Vesicular zinc staining extends down into the ventrolateral geniculate nucleus (vLGN) but was completely absent from the dorsolateral geniculate nucleus (dLGN).

Figure 3 Photomicrographs of representative hamster coronal slices showing levels of vesicular zinc staining in the suprachiasmatic nucleus $(\mathrm{SCN}, \mathrm{A}+\mathrm{B})$ and the intergeniculate leaflet (IGL, C+D) at ZT6 (A+C) and ZT18 (B+D). No significant differences were found between the time points, $p>0.05$.

Figure 4 Photomicrographs of representative hamster coronal slices showing vesicular zinc staining in the IGL from animals with intact retinas (A) and from enucleated animals (B). No significant difference was found between the two conditions, $p>0.05$. IGL staining was confirmed by matching an adjacent delineated NPY region $(C)$ to that of the presumed IGL region (B; boxed area). Matching blood vessel landmarks are denoted by $(*)$ for comparison and matching purposes. 
Figure 5 (A-C) Actograms from representative animals depicting the photic phase shift after intra-SCN injection with (A) vehicle (10\% DMSO shown) (B) $\mathrm{ZnCl}_{2}$ and (C) TPEN, denoted by a diamond $(\diamond)$ in the SCN10 min prior to a 15 min light pulse ( at late subjective night (CT18). Each horizontal line represents a day of wheel running as shown by the black vertical bars with subsequent days plotted below. The height of the bars is proportional to the number of wheel revolutions. (D) Mean phase shift $( \pm$ SEM) of hamsters after treatment with vehicle (average data of saline and DMSO for each animal), $\mathrm{ZnCl}_{2}$ and TPEN prior to a 15 -minute light pulse (LP) at CT18. For vehicle control, dark circles represent animals receiving 10\%DMSO, while open circles represent animals receiving saline. There was no significant difference in photic phase shifts between the treatments, $p>0.05$.

Figure 6 (A-C) Actograms from representative animals depicting the photic phase shift after bilateral intra-IGL injections with (A) vehicle (10\% DMSO shown) (B) TPEN and $\mathrm{ZnCl}_{2}$, denoted by a diamond $(\diamond)$ in the SCN10 min prior to a 15 min light pulse ( 40lux) at late subjective night (CT18). Each horizontal line represents a day of wheel running as shown by the black vertical bars with subsequent days plotted below. The height of the bars is proportional to the number of wheel revolutions. (C) Mean phase shift $( \pm$ SEM) of hamsters after treatment with vehicle (average data of saline and DMSO for each animal), $\mathrm{ZnCl}_{2}$ and TPEN prior to a 15-minute light pulse (LP) at CT18. There was no significant difference in photic phase shifts between the treatments, $p>0.05$.

Figure 7 Representative actograms from wildtype (A) and ZnT3-KO (B) mice in an LD cycle. Average waveforms of wheel running activity from all wildtype (C) and ZnT3-KO 
(D) mice over the days depicted in the actograms. The vertical gray bars represent the SEM across animals.

Figure 8 Representative actograms from wildtype (A,C) and ZnT3-KO (B,D) mice depicting phase shifts to a 15 min, 1250lux light pulse at CT16 (A,B) and CT22 (C,D). E) Mean shifts $( \pm$ SEM) from wildtype mice (white bars) and ZnT3-KO mice (gray bars). and individual shifts (circles). No significant difference in phase shifts were observed between the genotypes at either circadian phase examined.

Figure 9 Representative photomicrographs from wildtype (WT, left column) and ZnT3-KO mice (right column) depicting light induced cFos (top set) and mperl(bottom set) from animals given a 15 minute, 1250lux light pulse at CT16 (top row of each set) or CT22 (bottom row of each set). Immunoreactivity for arginine vasopressin (AVP, blue) was used to delineate the SCN shell, while immunoreactivity for gastrinreleasing peptide (GRP, red) was used to delineate the SCN core when counting cells with cFos immunoreactive nuclei (green). No significant differences were detected between the genotype for cFos or mperl expression at either circadian phase. 
bioRxiv preprint doi: https://doi.org/10.1101/790352; this version posted October 1,2019 . The copyright holder for this preprint (which was not certified by peer review) is the author/funder, who has granted bioRxiv a license to display the preprint in perpetuity. It is made available under aCC-BY-NC-ND 4.0 International license.
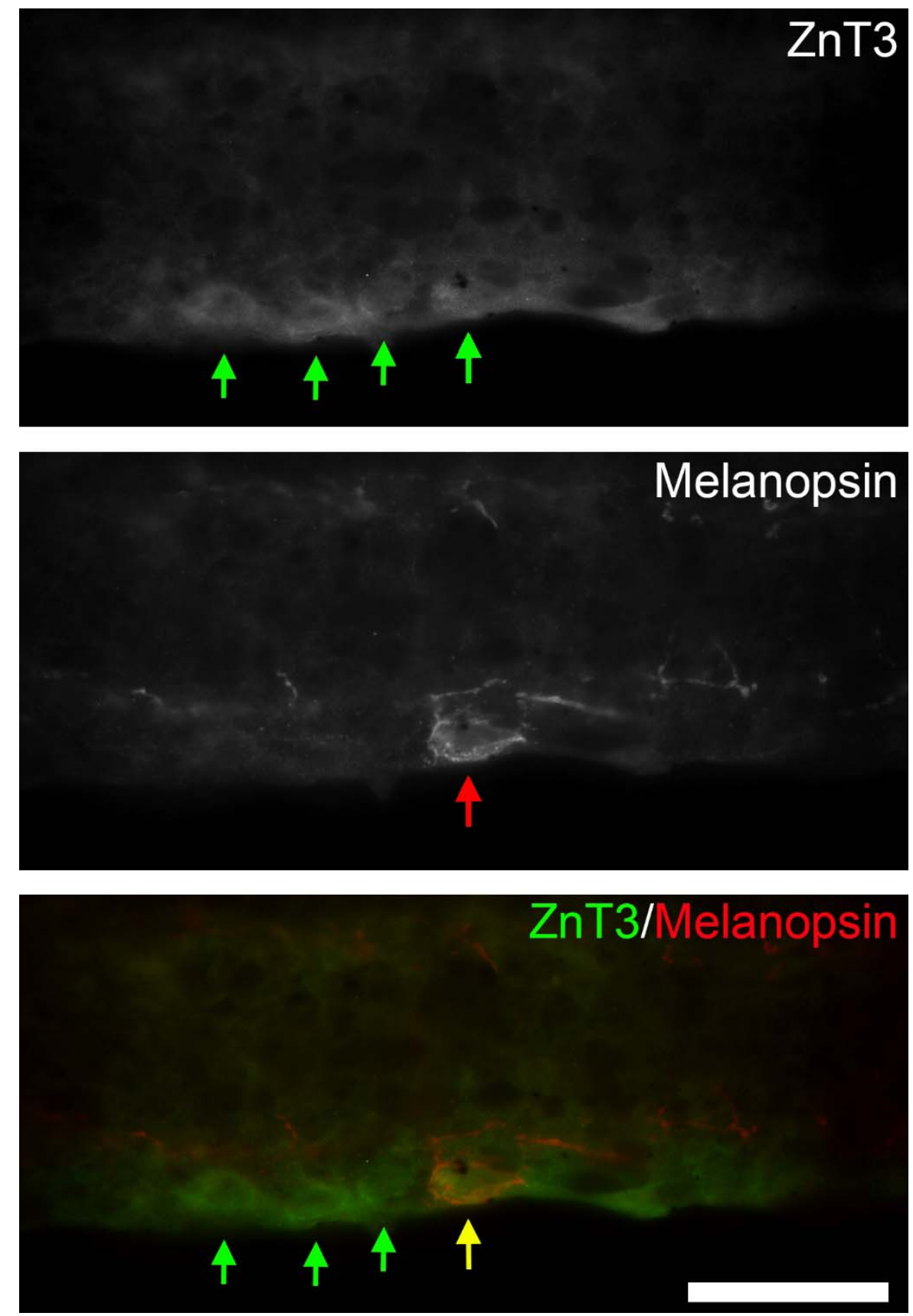

Figure 1 
bioRxiv preprint doi: https://doi.org/10.1101/790352; this version posted October 1,2019 . The copyright holder for this preprint (which was not certified by peer review) is the author/funder, who has granted bioRxiv a license to display the preprint in perpetuity. It is made available under aCC-BY-NC-ND 4.0 International license.

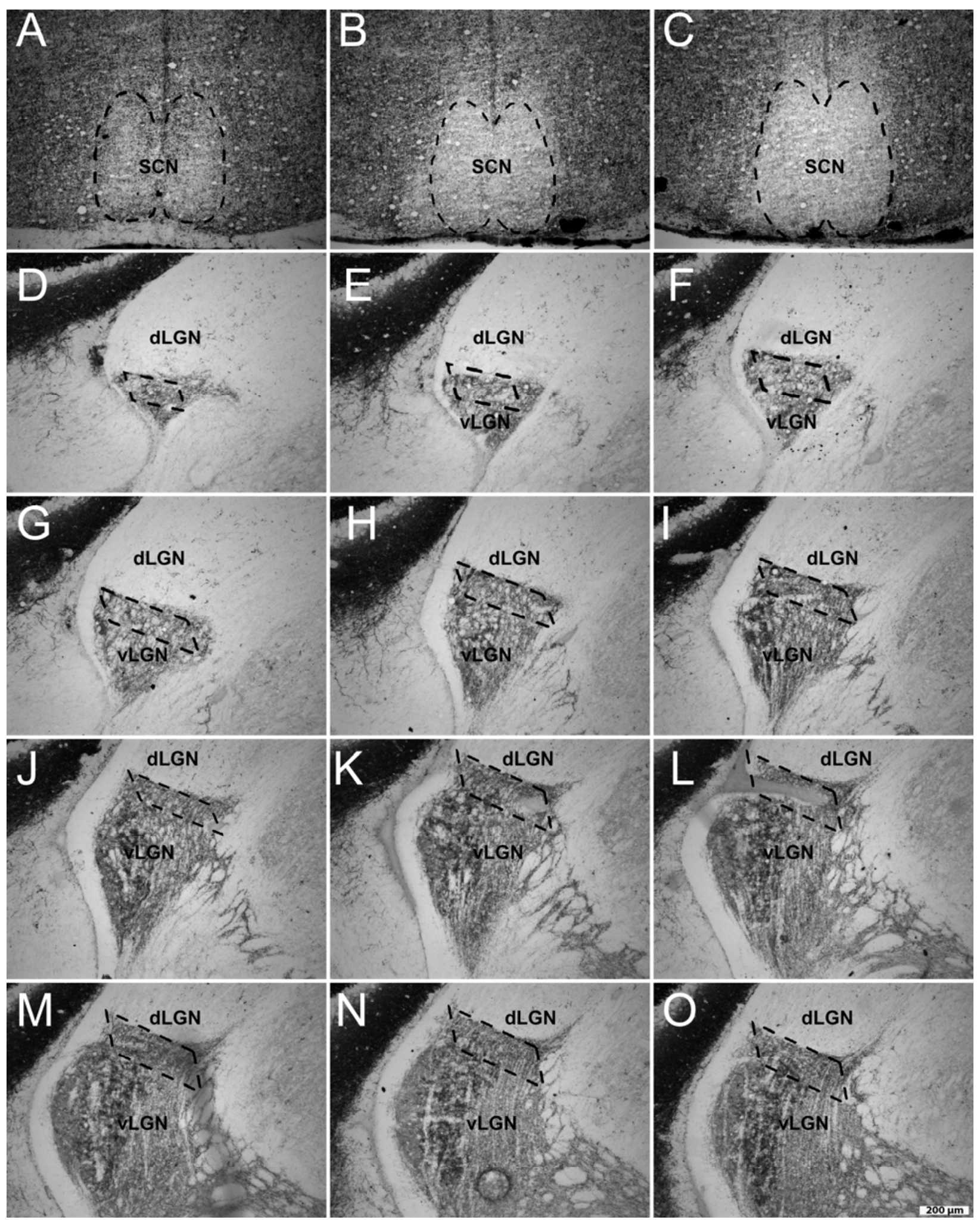

Figure 2 
bioRxiv preprint doi: https://doi.org/10.1101/790352; this version posted October 1, 2019. The copyright holder for this preprint (which was not certified by peer review) is the author/funder, who has granted bioRxiv a license to display the preprint in perpetuity. It is made available under aCC-BY-NC-ND 4.0 International license.

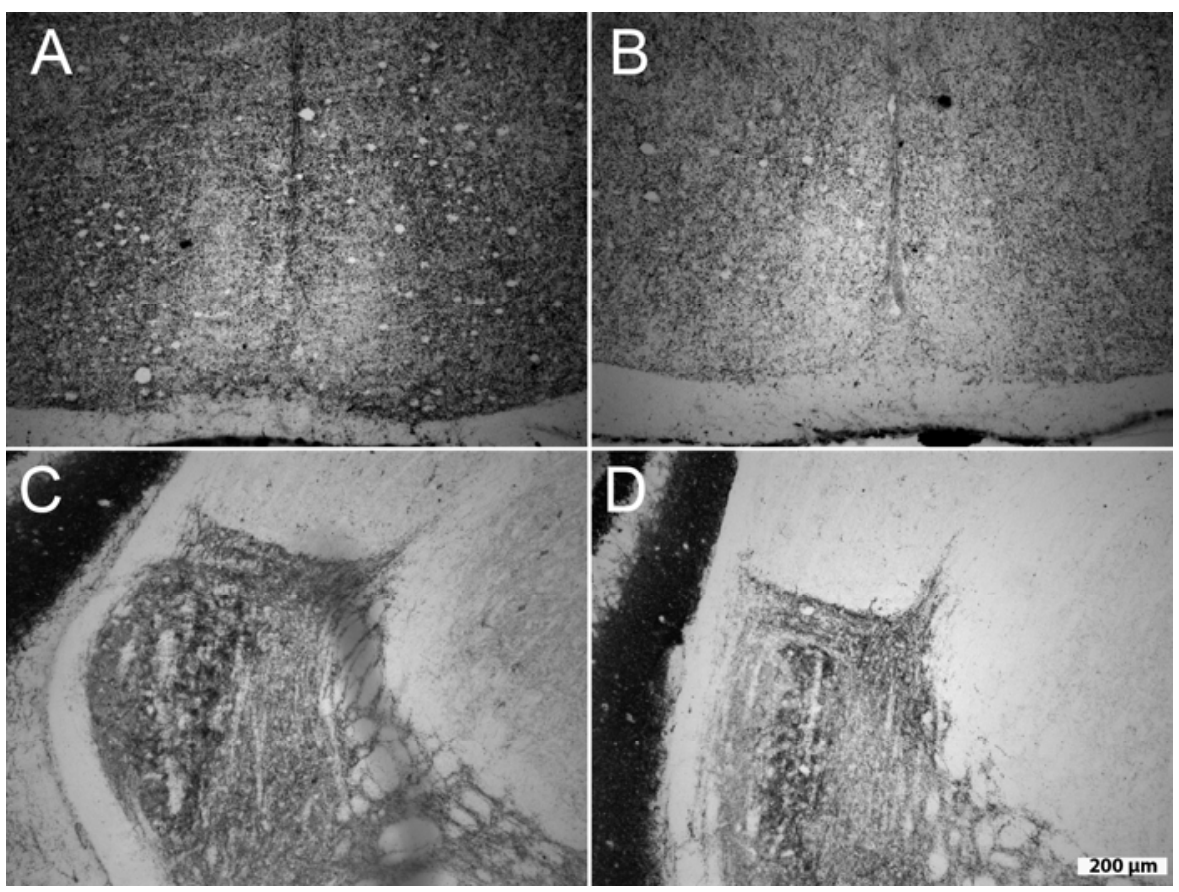

Figure 3 
bioRxiv preprint doi: https://doi.org/10.1101/790352; this version posted October 1, 2019. The copyright holder for this preprint (which was not certified by peer review) is the author/funder, who has granted bioRxiv a license to display the preprint in perpetuity. It is made available under aCC-BY-NC-ND 4.0 International license.

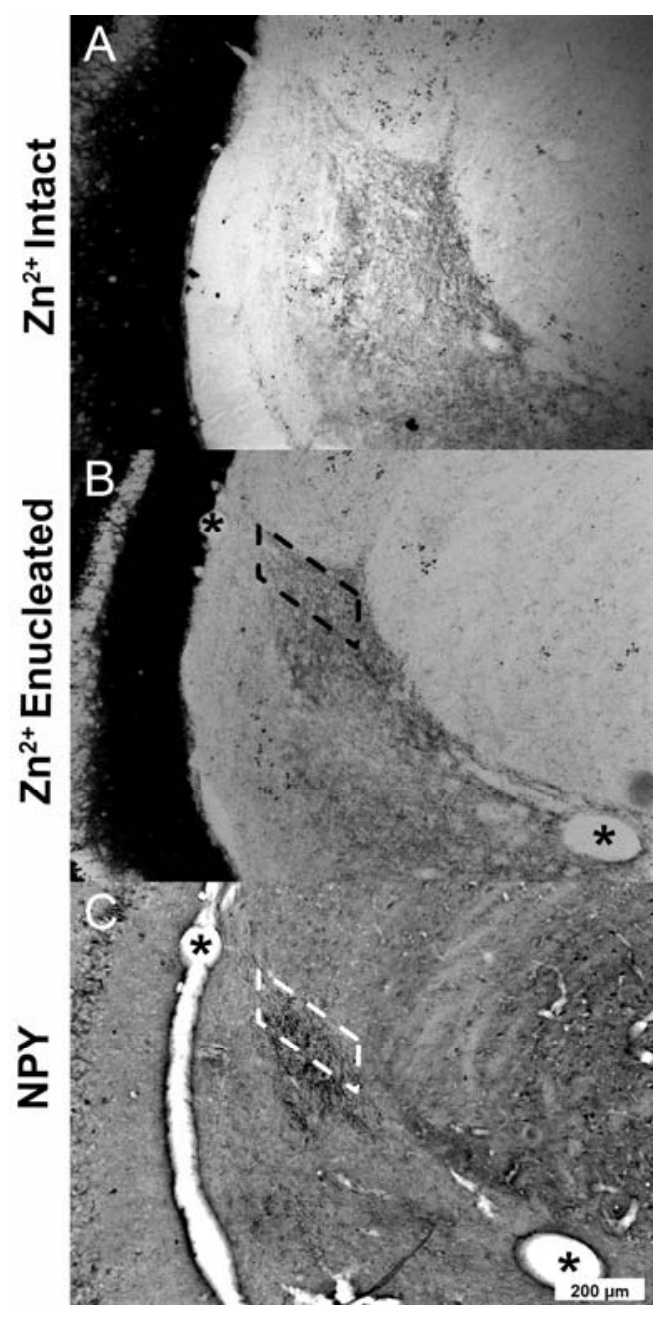

Figure 4 
bioRxiv preprint doi: https://doi.org/10.1101/790352; this version posted October 1, 2019. The copyright holder for this preprint (which was not certified by peer review) is the author/funder, who has granted bioRxiv a license to display the preprint in perpetuity. It is made available under aCC-BY-NC-ND 4.0 International license.
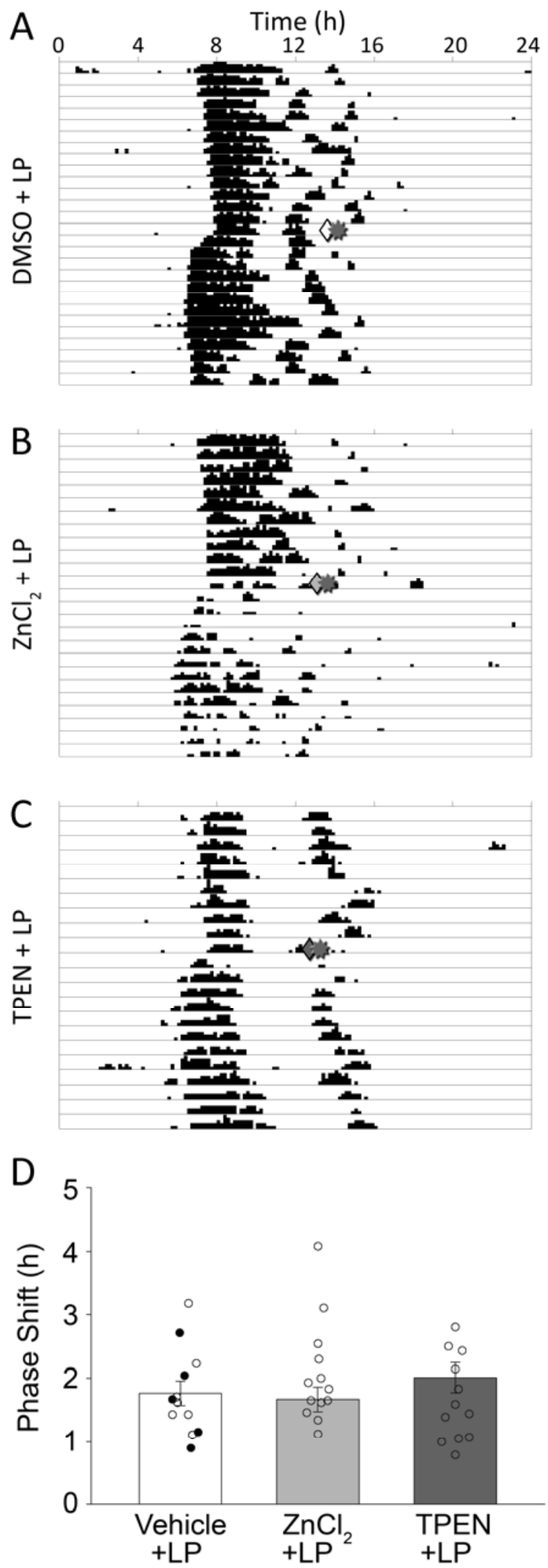

Figure 5 
bioRxiv preprint doi: https://doi.org/10.1101/790352; this version posted October 1, 2019. The copyright holder for this preprint (which was not certified by peer review) is the author/funder, who has granted bioRxiv a license to display the preprint in perpetuity. It is made available under aCC-BY-NC-ND 4.0 International license.

A

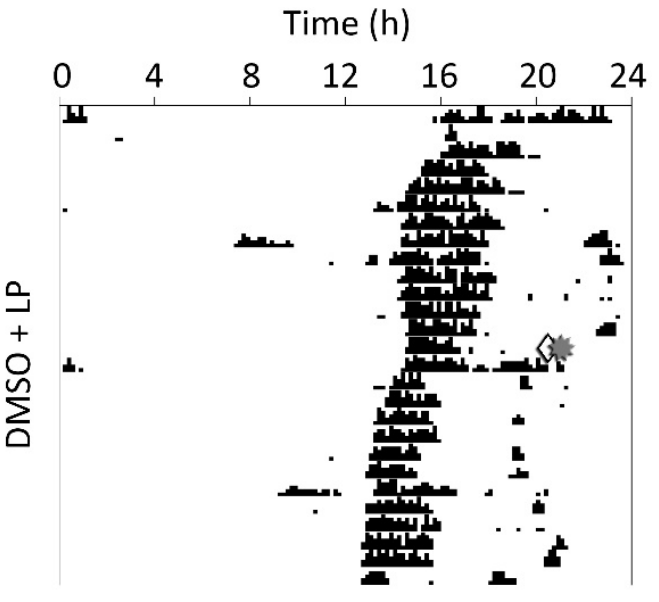

B
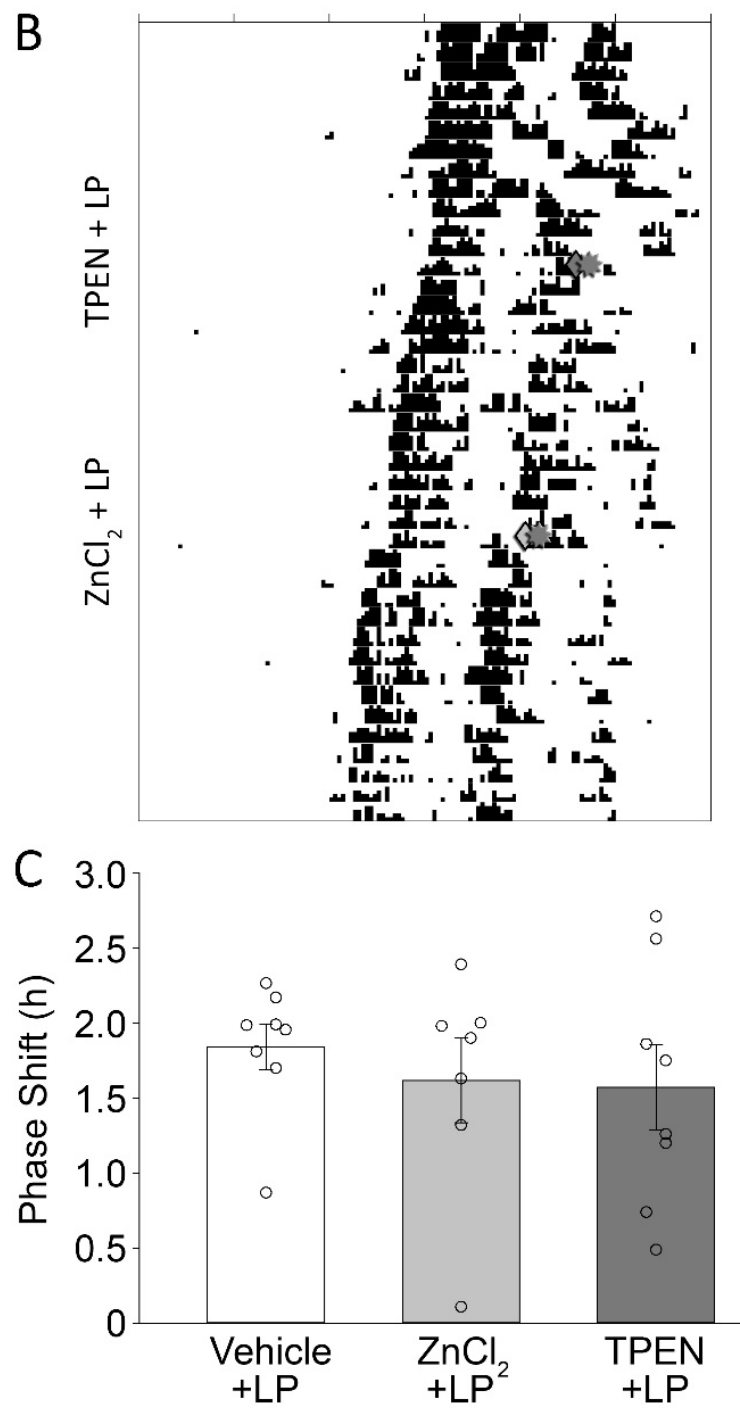

Figure 6 
bioRxiv preprint doi: https://doi.org/10.1101/790352; this version posted October 1, 2019. The copyright holder for this preprint (which was not certified by peer review) is the author/funder, who has granted bioRxiv a license to display the preprint in perpetuity. It is made available under aCC-BY-NC-ND 4.0 International license.
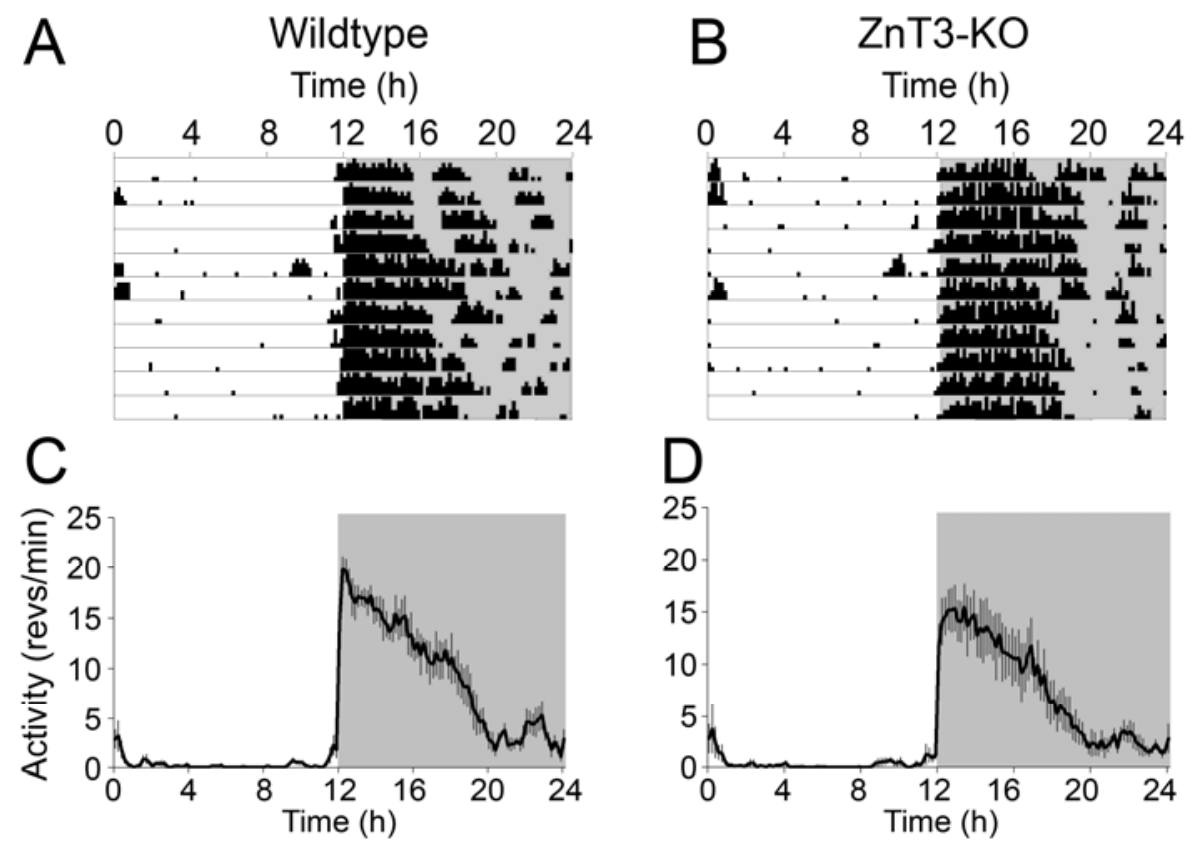

Figure 7 

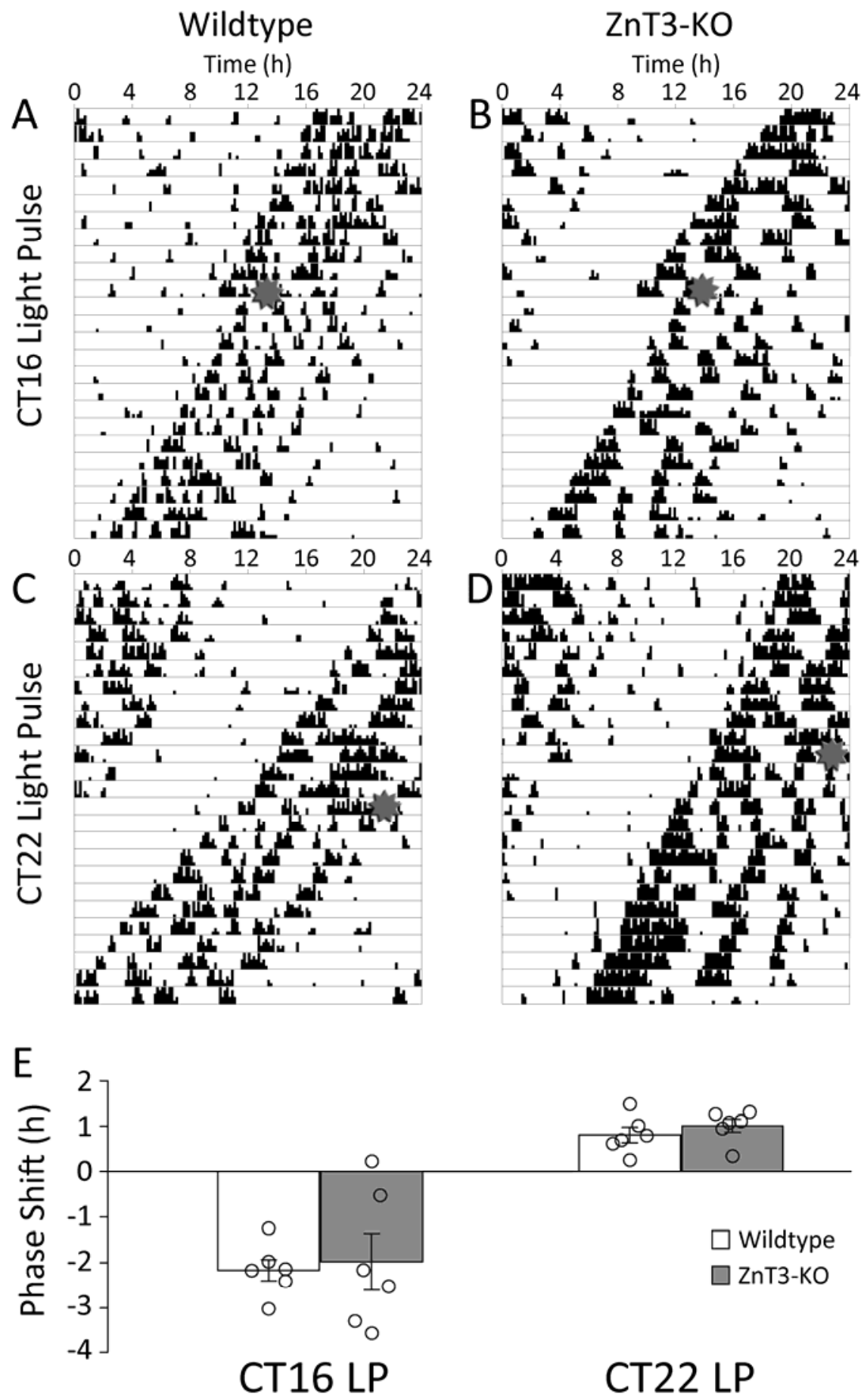

Figure 8 
bioRxiv preprint doi: https://doi.org/10.1101/790352; this version posted October 1,2019 . The copyright holder for this preprint (which was not certified by peer review) is the author/funder, who has granted bioRxiv a license to display the preprint in perpetuity. It is made available under aCC-BY-NC-ND 4.0 International license.
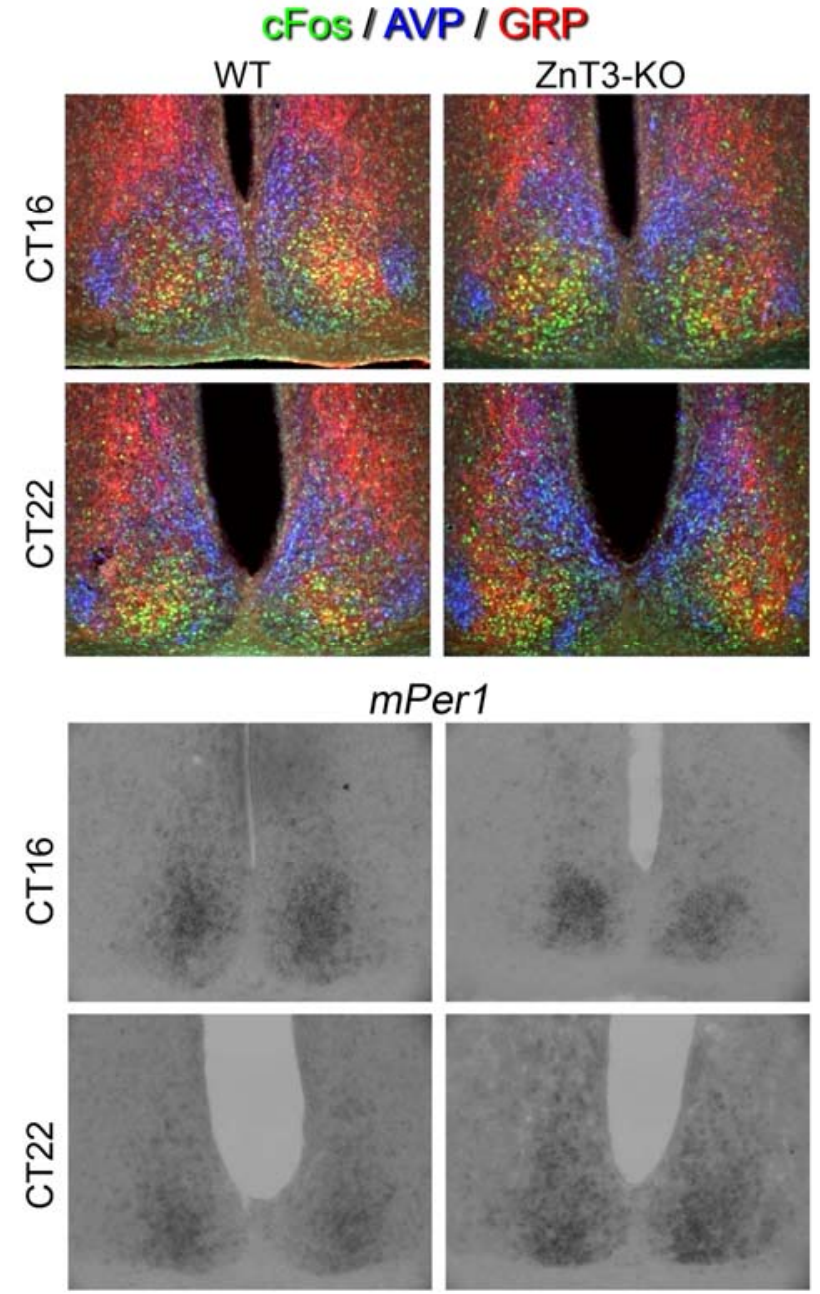

Figure 9 